\title{
Fuzzy MCDA for remediation of a uranium tailing
}

\author{
Danyl Pérez-Sánchez ${ }^{1}$, Antonio Jiménez ${ }^{2}$, Alfonso Mateos ${ }^{2}$, Alla Dvorzhak ${ }^{1}$ \\ ${ }^{1}$ Radiological Protection of the Public and Environment, CIEMAT, Spain \\ ${ }^{2}$ Decision Analysis and Statistics Group, UPM, Spain
}

\begin{abstract}
The Pridneprovsky Chemical Plant was a largest uranium processing enterprises, producing a huge amount of uranium residues. The Zapadnoe tailings site contains the majority of these residues. We propose a theoretical framework based on Multi-Criteria Decision Analysis and fuzzy logic to analyse different remediation alternatives for the Zapadnoe tailings, in which potentially conflicting economic, radiological, social and environmental objectives are simultaneously taken into account. An objective hierarchy is built that includes all the relevant aspects. Fuzzy rather than precise values are proposed for use to evaluate remediation alternatives against the different criteria and to quantify preferences, such as the weights representing the relative importance of criteria identified in the objective hierarchy. Finally, it is proposed that remediation alternatives should be evaluated by means of a fuzzy additive multi-attribute utility function and ranked on the basis of the respective trapezoidal fuzzy number representing their overall utility.
\end{abstract}

\section{Introduction}

The Zapadnoe uranium mill tailings site is situated in the south-western part of the main industrial site of the former Pridneprovsky Chemical Plant (PChP), located at Dneprodzerzhinsk (Ukraine). The tailings site operated from 1949 until 1954. The majority of the wastes were uranium mill tailings, disposed of using the hydraulic discharge method. The tailings site was covered in 2000 by an engineered multi-layer soil cover. As a result, the wastes are covered by a layer of nonradioactive backfill, composed from construction and industrial wastes, sand, clayey loam soils, clinker, rubbish etc. with a total thickness of 0.2 to $2.8 \mathrm{~m}$. The southern parts of the tailings have been covered by a 0.3 to $1.0 \mathrm{~m}$ thick layer of crushed stone and asphalt layer. The slopes of the tailings pile are covered by layers of clay loam and organic soil, with a combined thickness of $0.5-1.0 \mathrm{~m}$.

The tailings are situated on the slope of a sequence of the terraces of the Dnepr River. The general inclination of the ground surface is from the south to the north. 
The tailings themselves are located within the second terrace. The first (lower) terrace is situated to the north of the tailings. The third and fourth terraces are situated to the south of the waste site. The tailings site was surrounding by dikes that were not surfaced with protective impermeable screens and are currently buried below the layers of backfilled soil. The surface of the tailing pile is equipped with system for collecting runoff rainwater. This water goes to Konoplyanka River.

There are two aquifers at the Zapadnoe tailings site. The technogenic aquifer is a perched water horizon that is recharged by infiltration of atmospheric precipitation through the waste cover. The water from this aquifer infiltrates further down to the underlying aquifer in the alluvial deposits. The regional aquifer in the alluvial deposits is composed of alluvial sands, sandy loam and clay loam deposits, as well as loess deposits overlying the alluvial ones and the upper part of the fissured crystalline basement rocks underlying the alluvial deposits. The groundwater flow in the alluvial aquifer is directed to the north towards the Konoplyanka and the Dnepr.

In 2002-2004, as a result of a series of rainfall events, erosion of the surface and slopes of the protective dikes occurred (Economitor, 2007). Remedial works were carried out in 2005. These works included backfilling the eroded areas with clayey soil, and enforeing the slopes by a geo-technical polymer net material. The eroded surfaces were covered by an organic soil layer and planted with grasses. The surface run-off drainage system was also repaired.

The tailings site is surrounding by other industrial sites and technological communications lines that employ 2500 people. The surface of the tailing site is equipped warning signs and entry of personnel is prohibited, but the site is not fenced.

Two main sources of data currently exist regarding the physical, chemical and radiation characteristics of wastes disposed to the Zapadnoe tailings site. The first characterization studies were carried out in 2000 (Ecomonitor, 2007). Six characterization boreholes were drilled and the core material was subject to various lithological, chemical and radiometric analyses. The second characterization was carried out in 2009 in the framework of the National Program of Remediation of the PChP (UHMI, 2009). Information about radiation exposures due to contamination in soil, water and air was collected for various U-238 series radionuclides and $\mathrm{K}$ 40. Analyses of water samples were also performed to obtain information on contamination by chemically toxic materials

Discrepancies between the results of inventory studies carried out in 2000 and 2009 have been identified. In particular, the 2009 studies suggest that U-238 and Ra-226 concentrations in the wastes are about a factor of two higher than previously estimated. The estimated mean Th-230 activity is increased by a factor of about 3 and discrepancies are also observed for $\mathrm{Pb}-210$.

More recently, the context for a safety assessment of the Zapadnoe tailings site has been described in Bugay et al. 2012. The safety assessment itself was carried out by Ecomonitor and Geo-Eco-Consulting following the steps set out in the ENSURE project. It includes information on the operational history of the tailings 
site, on its engineering features, as well as on the chemical, physical and radioactive characteristics of the waste materials in the tailings. Environmental conditions (such as the geology, geomorphology and hydrogeological setting) and climate are also described.

Safety assessment can be considered as the starting point for an analysis of remediation alternatives, being equivalent to the no action alternative. The selection of a preferred remediation alternative is a complex decision-making problem in which factors additional to the radiological and chemical toxicity impacts of the wastes have to be taken into account. For example, the direct costs of the application and maintenance of remediation alternatives (manpower, consumables, equipment needed for application, management), the job creation effects and other indirect costs or benefits should be considered as economic criteria. Moreover, social impacts, as well as direct impacts on human health and safety, should be considered. These impacts include community satisfaction and the impact of remediation on the social characteristics of the neighbourhood.

\section{A fuzzy MCDA Approach}

The goal of Multi-Criteria Decision Analysis (MCDA) is to structure and simplify the task of making hard decisions to the extent that the nature of the decision permits (Belton, 1990).

What makes MCDA unique is the form in which these factors are quantified and formally incorporated into the problem analysis. Existing information, collected data, models and professional judgments are used to quantify the likelihoods of ranges of consequences, while utility theory is used to quantify preferences. The usual or traditional approach to MCDA calls for single or precise values for the different model inputs, i.e., for the weights as well as for the performances of the alternatives in terms of the identified criteria. However, we adopt a less demanding approach for the Decision-Maker (DM), who is able to provide fuzzy numbers instead of single values.

Fuzzy Logic (FL) introduced by Zadeh, 1965 is a mathematical tool for modelling using vague or imprecise measurements. In FL, a linguistic scale is usually built to characterize inputs to the model (Dursun, 2007). Each linguistic term is associated with a triangular or trapezoidal fuzzy number (Fig.1) and a fuzzy arithmetic is used to make the computations of model outputs. As shown, we consider the set of trapezoidal fuzzy numbers with support on $[0,1]$. The arithmetic proposed in (Xu et al., 2010) on TF $[0,1]$ is used to make computations. The resulting fuzzy number from such a computation is usually translated into a linguistic term in the previously defined scale by means of a similarity function (Vicente et al., 2013).

Following the MCDA methodology, an objective hierarchy in which all relevant criteria are included is first built and attributes are then established for the 
lowest-level objectives of the hierarchy to indicate to what extent they are achieved.

From the results of the safety assessment and other studies, the performance of each of the options in relation to each of the considered attributes has to be determined and translated into a trapezoidal fuzzy number. Also, the relative importance of the attributes in the objective hierarchy has to be represented by means of trapezoidal fuzzy numbers. Finally, a fuzzified additive utility function can be used to derive a global utility value for each option, on the basis of which remediation alternatives can be ranked.

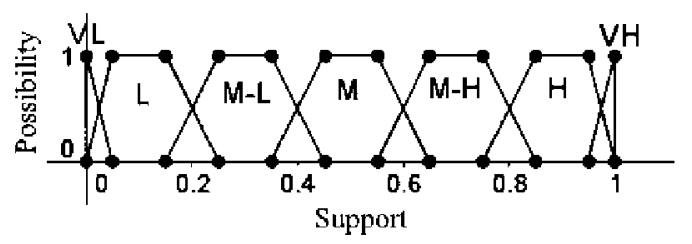

Fig.1. A fuzzy linguistic scale.

\section{Problem structuring}

To identify the criteria to be incorporated into the analysis, experts taking part in ENSURE II project were consulted and the literature on applications of MCDA for evaluating remediation alternatives (Brinkhoff, 2011) was reviewed, with a particular emphasis on applications to uranium mill tailing sites (Goldammer et al., 1999). On this basis, we built an objective hierarchy applicable to remediation options for the Zapadnoe tailings site (Fig. 2). There are four main top level criteria for the appropriate management of the Zapadnoe tailings site (global objective): Environmental impact, Radiological impact, Social impact and Economic impact.

The Environmental impact is due to contaminants discharged into surface waters that can impair the functioning of aquatic biota and the impact on groundwater bodies due to infiltration through the tailings to the underlying aquifer. Both radioactive and toxic chemical contamination are taken into account and measured in terms radiation dose or degree of chemical exposure. The doses and exposures derived from the safety assessment are adopted as reference values for the no action alternative and remediation options are evaluated in terms of differences from those values.

The Radiological impact is split into three sub-objectives. Public radiological impact refers to the doses received by the population through external exposure, inhalation (concentration in the air) and ingestion (via drinking water, food). It differentiates the doses received by the population during and after the implementation of the remediation alternative, leading to two new sub-objectives, respective- 
ly. The radiological impact on workers refers to radiation doses received by workers as a consequence of the process of implementing a remediation alternative. This objective is split into three sub-objectives accounting for the external dose (radiation exposure at the surface of the tailings site), and the doses received by inhalation and ingestion. To measure these objectives, the corresponding attributes take into account the number of workers needed to implement the remediation alternative, the number of hours each worker is exposed to the radiation and the radiation doses per hour through exposure at the surface, inhalation and ingestion, respectively.

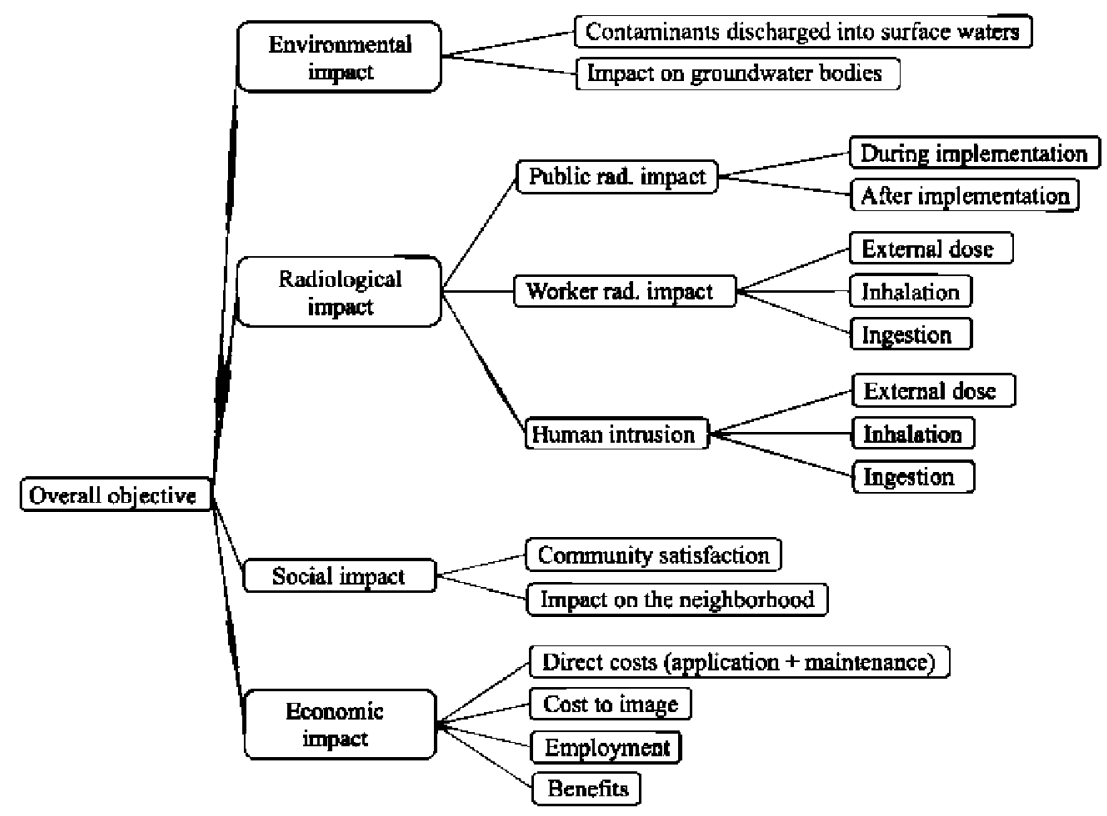

Fig.2. Objective hierarchy.

Finally, human intrusion refers to the radiation received by intruders at the $\mathrm{Za}$ padnoe tailings site. The objective is again split into three sub-objectives accounting for the external dose, and the doses received by inhalation and by ingestion. The corresponding attributes take into account an estimation of the number of intruders at the Zapadnoe tailings site per year on the basis of historical data, the average number of hours each intruder spent at the site by intrusion and the radiation doses per hour through exposure at the surface, inhalation and ingestion, respectively.

Social impact is split into community satisfaction and the impact on neighbourhoods or regions. Community satisfaction refers to how a remediation alternative is perceived by individuals belonging to a critical group living in the area and the impact on the neighbourhood accounts for the impact on the local community as a 
whole, including dust, light, noise, odour and vibration during the remediation works and associated with traffic, including weekday and weekend day- and night time operations. The fuzzy linguistic scale is used to quantify both social objectives.

Under economic impact, direct costs refer to the costs of the implementation and maintenance of a remediation alternative (manpower, consumables, equipment needed for implementation, management requirements). A monetary attribute is used for this aspect. Cost to image comprises indirect costs associated with a remediation alternative. It relates to public perceptions, e.g., a reluctance to purchase products from the area, even if uncontaminated, or a drop in tourism. Both the no action alternative and the various remediation options may have associated indirect costs. Employment corresponds to job creation in the implementation of a remediation alternative and afterwards. Short- and long-term jobs are taken into account and the corresponding attribute is measured in person-months.

Finally, benefits refer to direct economic benefits associated with the implementation of a remediation alternative (e.g., sale of waste materials for reuse).It is measured in monetary units. Note that all the criteria apply when evaluating remediation alternatives, but some of them, such as the impact on the neighbourhood, direct costs, employment or possible benefits are directly associated to the implementation of remediation alternatives and are not considered in the no action alternative. Imprecise estimates are allowed for by means of interval values in the fuzzy logic.

\section{Elicitation of preferences}

The Generic Multi-Attribute Analysis (GMAA) decision support system provides two procedures for assessing component utilities (Jiménez et al., 2006): directly constructing a piecewise linear utility function by providing the best and the worst attribute values and up to three intermediate values with their respective imprecise utilities; or on the basis of indifference judgments between lotteries and sure amounts. In both cases, the system permits value intervals to be specified as responses to the probability questions the DM is asked, which leads to fuzzy component utilities, see Fig.3. 


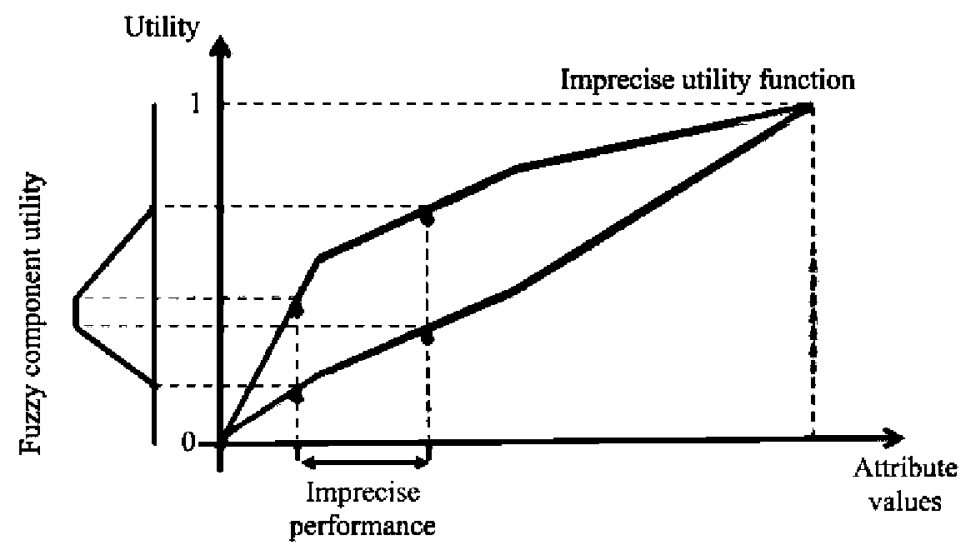

Fig.3. Fuzzy component utilities.

Weights representing the relative importance of criteria in the objective hierarchy have also to be elicited. We use a fuzzy adaptation of the procedure included in the GMAA system for eliciting weights based on trade-offs (Jiménez et al., 2006), in which the elicited individual has to make indifference judgments between lotteries and multiple sure amounts, permitting value intervals as responses. A direct assignment is also allowed by the use of weight intervals (rectangular fuzzy numbers) or using a fuzzy linguistic scale.

Once the relative importance of the objectives and attributes of those objectives has been rated along the branches of the hierarchy (Fig.2), the attribute weight can be assessed by multiplying the respective weights (represented by trapezoidal fuzzy numbers) of the objectives in the path from the root (global objective) to each leaf (attribute).

\section{Fuzzy evaluation of remediation alternatives}

Once the preferences have been quantified, the evaluation of remediation alternatives (including the no action alternative) can be performed by means of an additive multi-attribute utility function. The operators are those proposed in Xu et al. 2010. If the linguistic scale is used to value remediation alternatives in respect of a particular attribute, then the corresponding trapezoidal fuzzy numbers (Fig.1) are used as fuzzy component utilities.

Remediation alternatives are then ranked on the basis of the trapezoidal fuzzy numbers representing their overall utility. Methods for ranking fuzzy numbers are classified into four major classes according to Chen and Hwang, 1992. In this case, we propose to use a method based on a similarity function (Vicente et al., 
2013) in which the similarity of the fuzzy overall utility of each remediation alternative is computed regarding both the ideal $(1,1,1,1)$ and anti-ideal point $(0,0,0$, 0 ). The best-ranked alternative will be the most similar to the ideal point and, at the same time, the least similar to the anti-ideal point.

\section{Conclusions}

The evaluation of remediation alternatives in the Zapadnoe uranium mill-tailing site is a complex decision making problem involving environmental, radiological, social and economic criteria. The MCDA methodology provides a framework to structure the problem incorporating individual or group preferences. Moreover, vague or imprecise information is allowed for in the inputs to the decision-aiding process on the basis of fuzzy logic, which is less demanding for those who are elicited and makes the analysis suitable for group decision-making. Herein, we have set out a basis for such an evaluation. The evaluation itself is on-going and will be described in a subsequent publication.

\section{Acknowledgments}

This paper has been financially by the Spanish Ministry of Science and Innovation project (MTM 2011-28983-C03-03 and the Swedish International Development Cooperation Agency (SIDA) under the agreement CIEMAT-UPM-SSM for ENSURE project. The views herein shall not necessarily be taken to reflect the official opinion of SIDA.

\section{References}

Belton V (1990). Multiple criteria decision analysis practically the only way to choose. L.C. Hendry and R.W. Englese (Eds.), Operational Research Tutorial Papers 53-101, Birmingham: Operational Research Society.

Brinkhoff P (2011). Multi-criteria Analysis for Assessing Sustainability of Remedial Actions. Applications in Contaminated Land Development. Goteborg: Chalmers University of Technology.

Bugay D, Voitsekhovitch O, Lavrova A, Skalsky A, Tkachenko E (2012). Definition of the assessment context and scenarios for the selected cases. Data analyses and data collection. Case A Zapadnoe tailings. Report on the Project ENSURE-II: Work Package 2, Kiev: Ecomonitor.

Chen S.J Hwang C.L (1992). Fuzzy Multiple Attribute Decision Making: Methods and Applications. New York: Springer. 
Dursun M (2007). Evaluating solid waste management scenarios using fuzzy multi-criteria decision making approaches. Thesis of Master of Science. Istanbul: Galatasaray University.

Goldammer W, Nüsser A, Bütow E, Lühr H.P (1999). Integrated assessment of radiological and non-radiological risks at contaminated sites. Mathematische Geologie, 3, 53-72.

Jiménez A, Ríos-Insua S, Mateos A (2006). A Generic Multiattribute Analysis System. Computers and Operations Research, 33, 1081-1101.

UHMI (2009). Analytical measurements of samples of material from tailings according to parameters of spectrum of priority alpha- and gamma-emitting radionuclides of U-Th series using methods of low background semiconductor alpha- and gammaspectroscopy. Final report on contract No.31 with SE Baryer, Kiev: UHMI Institute.

Vicente E, Mateos A, Jiménez A (2013). A new similarity function for generalized trapezoidal fuzzy numbers. Lecture Notes in Computer Science, 7895, 400-411.

Zadeh L.A (1965). Fuzzy sets. Information and Control, 8, 338-353.

Xu Z, Shang S, Qian W, Shu W (2010). A method for fuzzy risk analysis based on the new similarity of trapezoidal fuzzy numbers. Expert Systems with Applications, 37, 1920 1927. 